\title{
Impact of PV Distributed Generation on Loop Distribution Network
}

\author{
Mohammad A. Alrumaih1, Abdullah M. Al-Shaalan² \\ ${ }^{1}$ Saudi Electricity Company Riyadh, Riyadh, Saudi Arabia \\ ${ }^{2}$ King Saud University Riyadh, Riyadh, Saudi Arabia \\ Email: shaalan123@gmail.com
}

How to cite this paper: Alrumaih, M.A. and Al-Shaalan, A.M. (2019) Impact of PV Distributed Generation on Loop Distribution Network. Journal of Power and Energy Engineering, 7, 27-42.

https://doi.org/10.4236/jpee.2019.78002

Received: June 19, 2019

Accepted: August 26, 2019

Published: August 29, 2019

Copyright () 2019 by author(s) and Scientific Research Publishing Inc. This work is licensed under the Creative Commons Attribution International License (CC BY 4.0).

http://creativecommons.org/licenses/by/4.0/

cc) (i) Open Access

\begin{abstract}
The rapid spreading of the Photovoltaic (PV) Systems as Distributed Generation (DG) in medium and low voltage networks created many effects and changes on the existing power system networks. In this work, two methods have been used and applied to determine the optimal allocation and sizing of the PV to be installed as DGs (ranging from $250 \mathrm{~kW}$ up to $3 \mathrm{MW}$ ). The first one is to determine the location according to the maximal power losses reduction over the feeder. The second one is by using the Harmony Search Algorithm which is claimed to be a powerful technique for optimal allocation of PV systems. The results of the two techniques were compared and found to be nearly closed. Furthermore, investigation on the effects on the feeder in terms of voltage levels, power factor readings, and short circuit current levels has been done. All calculations and simulations are conducted by using the MATLAB Simulation Program. Some field calculations and observations have been expended in order to substantiate the research findings and validation.
\end{abstract}

\section{Keywords}

Distributed Generation (DG), Feeder, Photovoltaic System (PV), Power Factor, Ring Main Unit (RMU), Short Circuit Current, Voltage Instability

\section{Introduction}

The rapid growth in power demand in the Kingdom of Saudi Arabia has created many challenges to meet and satisfy that ever-growing and increasing demand. Using the fossil fuel to generate electricity will emit more harmful gases to the atmosphere and to the surrounding environment. Building huge power plants will enhance the transmission lines congestion and yield losses in the network as well. Of the proposed solutions is the Distributed Generation (DG), which is 
based on the idea of bringing the generation just as near as possible to the load centers. DG will not be efficient unless the generators are suitable and safe to be installed in distribution network, where the huge power generators cannot be erected and installed. DG can be defined as a small scale technology used to provide source of active power, where it can be located near end-user or near to the loads in the network [1].

The size of generation which can be considered as DG is varying depending on the organization, but yet all values are convergent and not exceeding $20 \mathrm{MW}$.

Some countries have a good promising potential for wind energy like Germany. Others, such as Saudi Arabia, have the availability of sunshine for most of the days. As a result of the rapid improvement in technologies for adopting renewable energy facilities, Solar Photovoltaic (PV) systems account for the biggest percentage among other DG technologies. More than 90 percent of the installed distributed generation in the United States today is solar sources [2].

The presence of PV generation in distribution system has many advantages as being an environment friend, the simplicity of the system itself and the wide range of sizes which can be installed is a great advantage over the other power generation methods. From the power quality point of view, the PV systems are used in many cases to raise the bus voltage at the far end of the radial distribution feeders and decreasing the losses over the feeder [3].

The main disadvantages of the DG systems are the increasing levels of short circuit current and the voltage variations and fluctuation issues. The behavior of DG itself will also have an impact on system operation and protection. The uncertainty of power flow will also increase a certain difficulty for power system protection operational setting [4].

This proposed work aims at finding the optimal allocation and sizing of the PV system to be installed in a loop distribution underground feeder [5], then, investigating and analyzing the effect of installing the PV systems on the same feeder. The PV systems are coupled to the primary bus at the distribution substation which also connected to the utility system. The impact of different levels of PV penetration on voltage levels, power factor readings, and short circuit current levels will be investigated and assessed using the same distribution feeder modeled in MATLAB simulation tool.

\section{Case Study Circuit}

Saudi Electricity Company (SEC) owns the whole concession of the distribution network in the Kingdom of Saudi Arabia. Furthermore, 85\% of the distribution network all over the kingdom is designed and constructed similar standards [6]. Riyadh City (the Kingdom capital) constitutes nearly 15\% of the overall SEC distribution network. For this reason, it has been selected to be the most appropriate case-study application for the proposed methodology of this work.

\subsection{Riyadh City Medium Voltage Network}

MV distribution network in Riyadh City is designed and constructed in loops. 
For each point on the circuit, whether it has one distribution transformer or more, a Ring Main Unit switch (RMU) is installed to maintain a high level of reliability on the MV network. Thus, any $13.8 \mathrm{kV}$ cable of the MV network can be isolated without interrupting the power supply on other equipment. Figure 1 shows a simplified single line diagram of the exciting underground loop MV network.

\subsection{Network Specifications}

The standards used to build the MV network in Saudi Arabia were based on IEEE, IEC AEIC standards [6] [7]. Table 1 shows the specifications of the 13.8 $\mathrm{kV}$ network.

\subsection{Case Study Circuit Specifications}

The selected circuit is feeding a mixed load. $13 \%$ of the actual load in the circuit is a commercial load while $87 \%$ is a residential load.

The length of the circuit is 16,562 meters feeding 43 transformers (13.8 $\mathrm{kV} / \mathrm{LV}$ ). Figure 2 shows a simple topology of the circuit. Every RMU is connecting a load to the circuit through a distribution transformer. The main currents passing through the circuit are $I_{1}$ and $I_{2}$, while $I_{3}$ is feeding only one RMU and planned to be as an alternative source. The current $I_{1}$ and $I_{2}$ are shown in Figure 3.

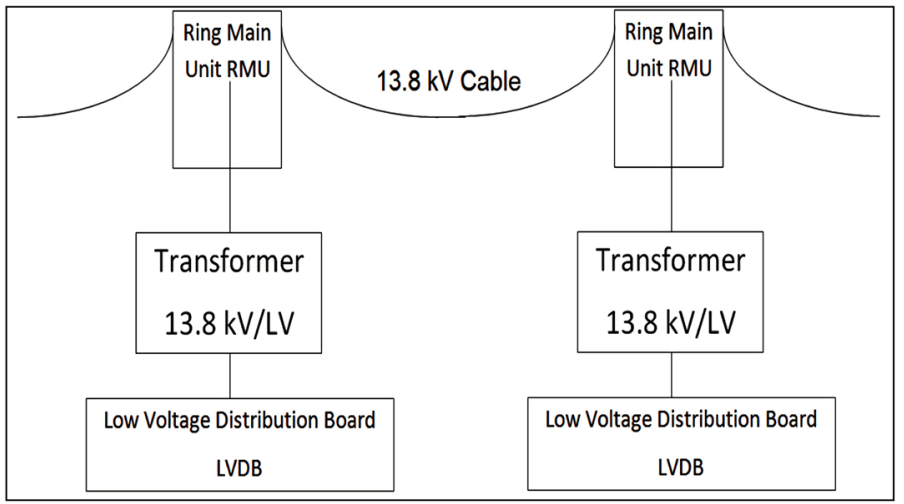

Figure 1. Single line diagram of the exciting U/G loop MV network of Riyadh City.

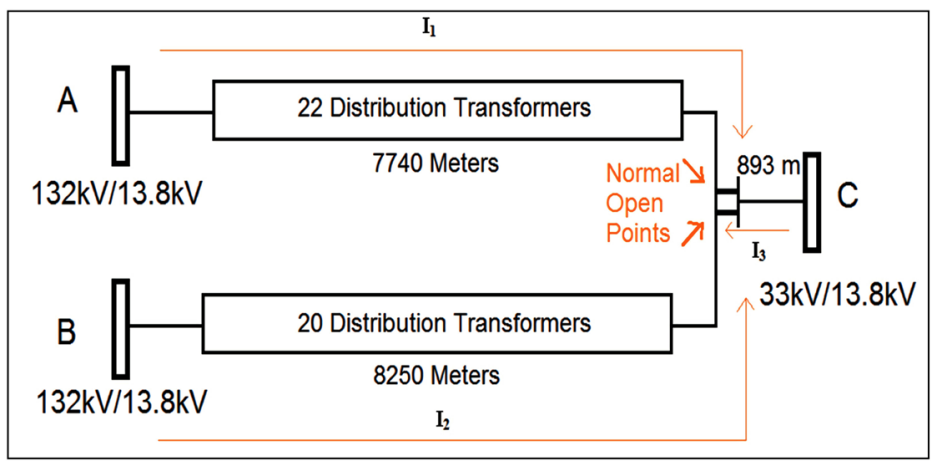

Figure 2. Simple single line diagram of the case study circuit. 
Table 1. $13.8 \mathrm{kV}$ network specifications.

\begin{tabular}{|c|c|c|}
\hline Voltage & System Nominal Voltage & $13.8 \mathrm{kV}$ \\
\hline \multirow{4}{*}{ Cable } & Cable Size & $300 \mathrm{~mm}^{2}$ Cupper \\
\hline & Cable Rated Current & $390 \mathrm{~A}$ \\
\hline & Cable Normal Current & $290 \mathrm{~A}$ \\
\hline & Resistance $\Omega / \mathrm{Km}$ (Copper) & $0.0607 \Omega / \mathrm{km}$ \\
\hline \multirow{2}{*}{ Primary Station Bus Bar } & Rated Short-Time Withstand Current & $21 \mathrm{kA}$ \\
\hline & Rated Power Frequency Withstand Voltage & $50 \mathrm{kV} \mathrm{rms}$ \\
\hline \multirow{4}{*}{ Breaker } & Rated Normal Current & $400 \mathrm{~A}$ \\
\hline & $\begin{array}{l}\text { Rated Short-Time Withstand Current } \\
\quad(33 / 13.8 \mathrm{kV} \text { Primary Stations })\end{array}$ & $21 \mathrm{kA}$ \\
\hline & $\begin{array}{l}\text { Rated Short-Time Withstand Current (132/13.8 } \\
\text { kV Primary Stations) }\end{array}$ & $25 \mathrm{kA}$ \\
\hline & Rated Power Frequency Withstand Voltage & $50 \mathrm{kV} \mathrm{rms}$ \\
\hline \multirow{2}{*}{ Ring Main Units (RMU) } & Bus Bar Rated Normal Current & $630 \mathrm{~A}$ \\
\hline & Bus Bar Rated Normal Voltage & $13.8 \mathrm{kV}$ \\
\hline
\end{tabular}

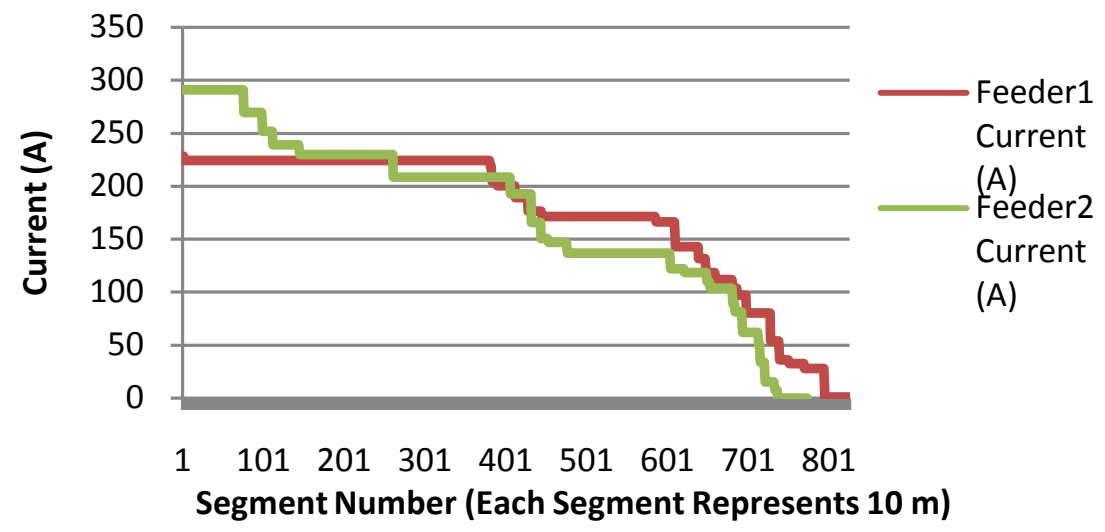

Figure 3. Current reading for the two feeders over the feeder's length.

A switch (Ring Main Unit) is used to connect the PV systems to the network. This makes these PV systems more controllable by the utility company. Figure 4 , shows a simplified single line diagram of the connection criteria

\section{Allocation and Sizing of PV Systems}

Many papers and researches have been presented on the matter of determining the allocation and sizing of the PV systems. Different methods have been introduced for Optimal Distributed Generation Allocation (ODGP). Three broad approaches are usually used in sizing and allocation of DG units in distribution networks. These are based on analytical, numerical and heuristic methods [8].

The used numerical method in this research is to develop a MATLAB code that will calculate the power losses at each part of the distribution feeder. The distribution feeder will be divided into segments; each segment is a 10 meters 


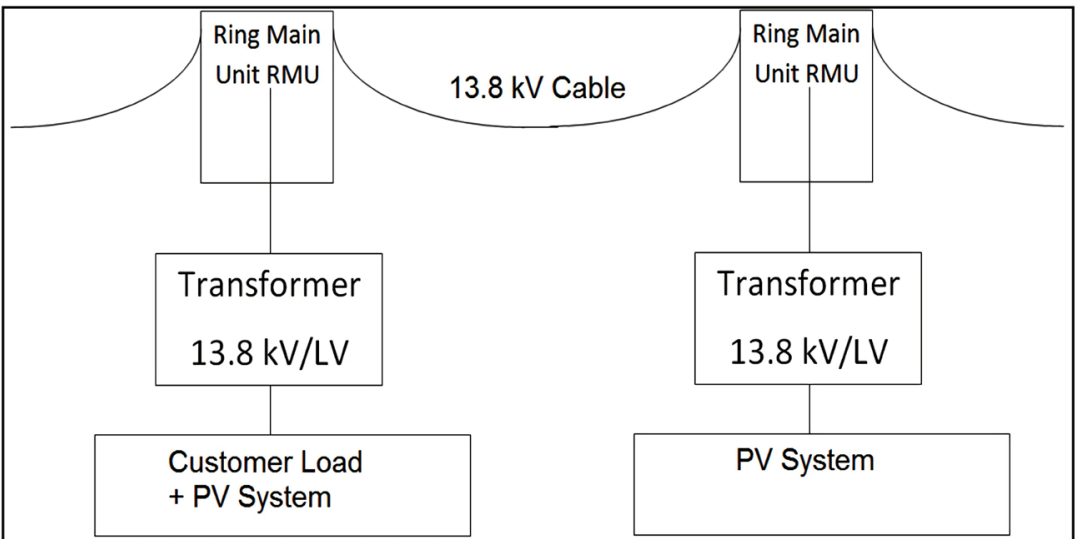

Figure 4. PV system connection.

long. Code's loops will install the PV system at every segment each time, and then calculate the power losses for the whole feeder. The optimal bus to connect the PV system is the one with the least power losses for the total feeder. The method is called Maximal Power Losses Reduction. For the sake of comparison, another method will be used to determine the optimal allocation of PV system, which is Harmony Search Algorithm (HS). HS is depending on random inputs then optimizes the new results based on previous results.

\subsection{Maximal Power Losses Reduction}

\subsubsection{Technical Work Preparation}

Only Feeder 1 and Feeder 2 will be considered to install PV systems at, the spare feeder is considered to be spare. Each 10 meters is considered to be a segment, thus Feeder 1 has 774 segments and Feeder 2 has 825 segments.

The current passing through each segment consists of two elements, the current coming from primary station and the current generated from the PV system. There are two cases:

1) The two current added together to feed the same segment as described in Figure 5.

2) The two currents are separated; each segment is fed either from the current coming from the primary station or from the current generated from the PV system, as shown in Figure 6.

If the capacity of the PV system is more than the load, as shown in Figure 7, then, $I_{P V}$, the current generated by the solar system, will be divided into two currents $I_{P V 1}$ and $I_{P V 2}$, and,

$$
I_{P V}=I_{P V 1}+I_{P V 2}
$$

The resistance of copper cables $300 \mathrm{~mm}^{2}$ is $0.0607 \Omega / \mathrm{Km}$. Thus the resistance for each segment is $0.607 \times 10^{-3} \Omega /$ Segment. Then,

$$
P L_{\text {Seg }}=I_{\text {Seg }}^{2} \times 0.607 \times 10^{-3}
$$

where $P L_{S e g}$ is the power lost for each segment $(10 \mathrm{~m}), I_{S e g}$ is the current passing through each segment. 


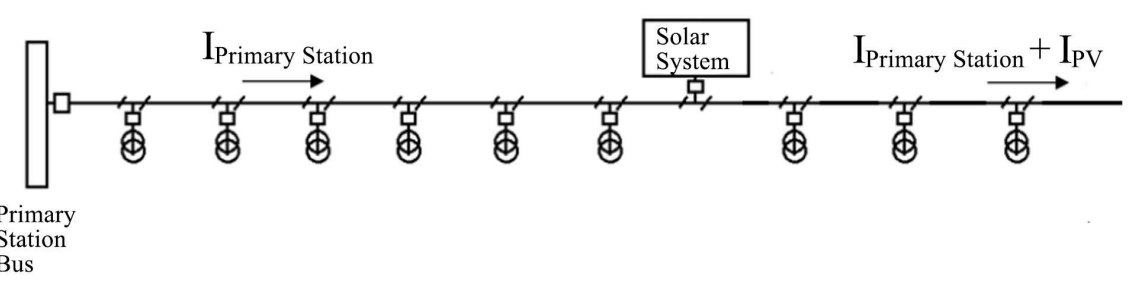

Figure 5. Added primary station current and solar system current.

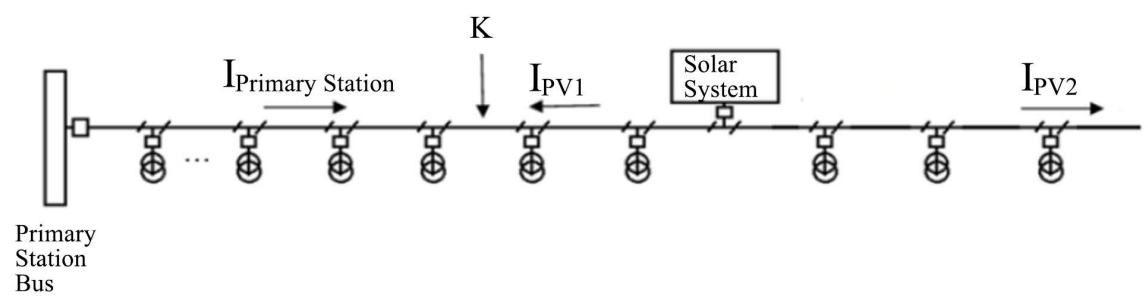

Figure 6. Primary station current and solar system current are separated.

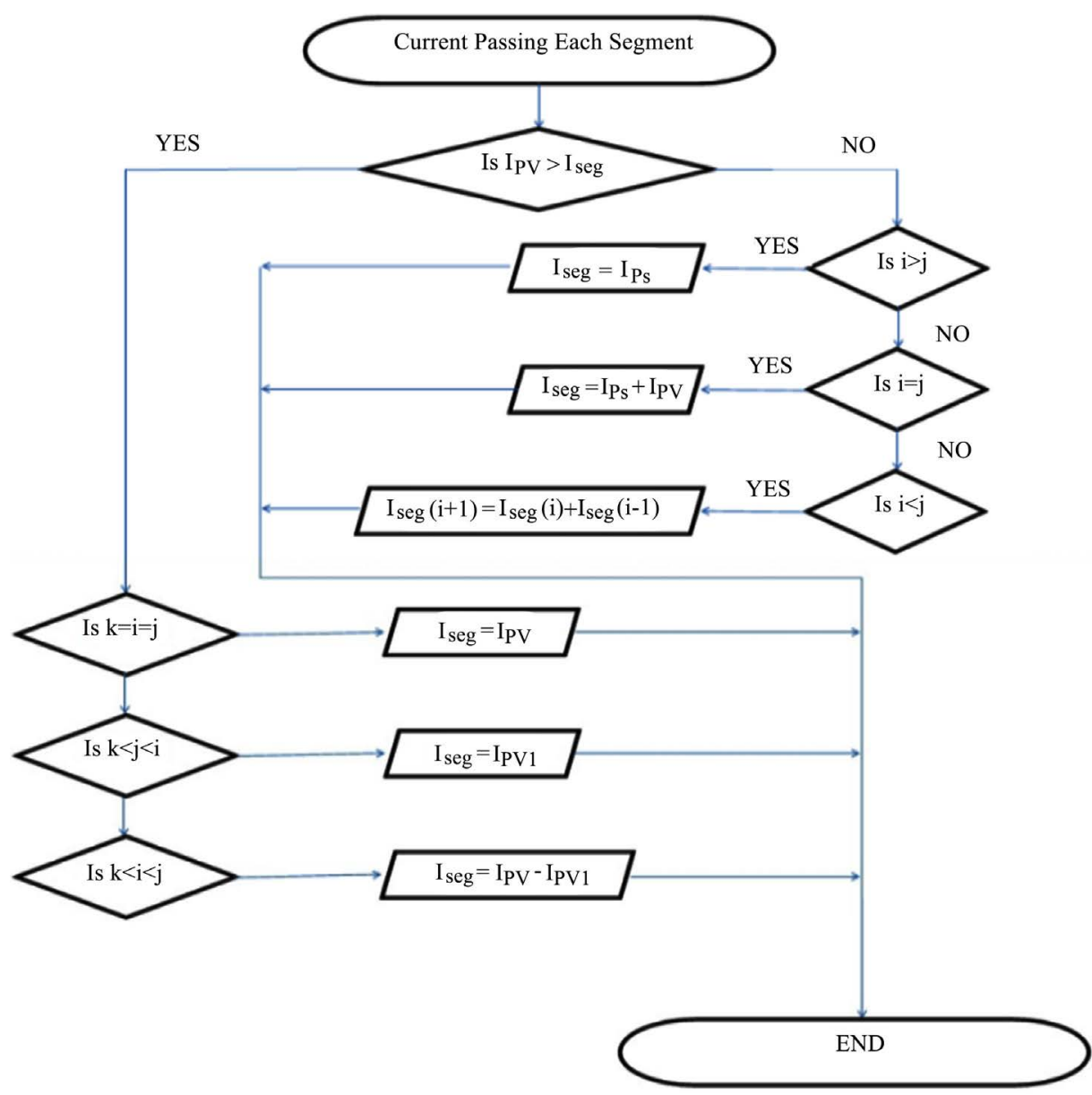

Figure 7. Maximal power loss reduction process flowchart.

The load value for each distribution transformer is measured and provided from SEC and shown in Figure 5. Then, the current can be found using the following formula. 


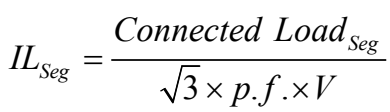

where Connected Load Seg $_{\text {is }}$ is the connected load for each segment (kW), which is provided from Saudi Electricity Company SEC data, as shown in Figure 5, $p . f$. is the Power factor, $V$ is the voltage $(\mathrm{V})$.

A loop is created to change the location of PV system and install it at a specific segment in each loop iteration. This loop is called PV location loop (i). A second loop initiated to calculate the power losses at each segment, which called segment power losses loop $(j)$.

The primary station current which is feeding part of the feeder is equal to:

$$
I_{P S}=291.82-I_{P V}
$$

where $I_{P S}$ is the current coming from the primary station (A), $I_{P V}$ is the current generated from the PV system (A), 291.82 is the actual reading of current of Feeder 1 (A), for feeder 2, the actual reading of current $228.48 \mathrm{~A}$.

If $i=j$, means the iteration of $\mathrm{PV}$ system location and the iteration of segment power losses are equal. The current passing through the segment will be equal to:

$$
I_{\text {Seg }}=I_{P S}+I_{P V}
$$

If $i>j$, then the current passing the segment will be:

$$
I_{\text {Seg }}=I_{P S}
$$

which means that the segments before the location of installing the PV system are feeding only from the primary station source.

If $i<j$, then the current passing the segment will be the difference in current in previous segment, to find the current passing the next segment:

$$
I_{\text {Seg }}(j+1)=I_{\text {Seg }}(j)-\left[\frac{\text { Total Load }_{\text {Seg }}}{\sqrt{3} \times p \cdot f . \times V}(j)-\frac{\text { Total Load }_{\text {Seg }}}{\sqrt{3} \times p \cdot f . \times V}(j-1)\right]
$$

where the total load is the summation of power losses and the actual load of the segment,

$$
\text { Total load }_{\text {Seg }}=\text { Connected }_{\text {Load }} \text { Seg }+P L_{\text {Seg }}
$$

The last part of the feeder where the current feeding the load, is only the current generated from the PV system, as shown in Figure 7. The segment $K$ is considered to be the first segment to be fed by $I_{P V}$. In other words, the point $K$ is the point which after it only $I_{P V}$ is feeding the circuit. The equations will be different since the current direction is different. There are three cases to be considered:

1) $K=j=i$

In this case,

$$
I_{\text {Seg }}=I_{P V}
$$

The current passing through each segment will be calculated by the following equation. 


$$
I_{P V}(j+1)=I_{P V}(j)-\left[\frac{\text { Total Load }_{\text {Seg }}}{\sqrt{3} \times p \cdot f . \times V}(j)-\frac{\text { Total Load }_{\text {Seg }}}{\sqrt{3} \times p \cdot f . \times V}(j-1)\right]
$$

2) $K<j<i$

In the case when the iteration of $(j)$ is smaller than the iteration of $(i)$, the current passing each segment will be calculated using the following equations,

$$
I L_{\text {Seg }}=\frac{\sum_{\text {Seg }=K}^{j}{\text { Connected } \text { Load }_{\text {Seg }}}_{\sqrt{3} \times p . f . \times V}}{\sqrt{3} \text {. }}
$$

The power loss is calculated after that by Equation (2), and then the total power of the segment is equal to,

$$
\text { Total Power } \text { Seg }=\sum_{\text {Seg }=K}^{j}\left[\text { Connected Load } \text { Seg }_{\text {Seg }}+P L_{\text {Seg }}\right]
$$

Then $I_{P V}$ is calculated using the following equation,

$$
I_{P V 1}=\frac{\text { Total power }_{\text {Seg }}}{\sqrt{3} \times p \cdot f \cdot \times V}
$$

And,

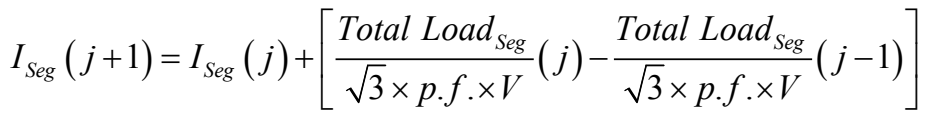

3) $K<i<j$

If the iteration of PV system location $(i)$ is smaller than the iteration of the segment power losses $(j)$,

$$
I_{P V 2}=I_{P V}-I_{P V 1}
$$

The PV system will be installed at a specific segment, and then the power losses will be calculated for each segment. The total power losses of the feeder are determined by adding all the power losses in all segments. After that, the location of PV system will be changed to the next segment and then the power losses of the feeder will be calculated using the same procedure.

Different sizes of the PV system will be studied, 0.25, 0.5, 0.75, 1, 1.5, 2, 2.5 and $3 \mathrm{MW}$. Figure 7 illustrates the process.

\subsubsection{Feeder 1 Result}

Multiple situations of connecting several sizes of PV systems have been studied. The calculation is done based on the peak load. For example, if a 1 MW PV system were installed in Feeder 1 of the circuit, the optimal location would be at segment 715 (means at $7150 \mathrm{~m}$ ). The power loss of MV cable in Feeder 1 of the circuit would record $11.961 \mathrm{~kW}$, while the total load of Feeder 1 is $6.277 \mathrm{MW}$. The losses percentage is $0.1908 \%$. Figure 8 shows numbers of cases which were studied to determine the optimal location of the PV systems.

For Feeder 1 of the circuit, in all the cases, the optimal location to install a PV system of size $3 \mathrm{MW}$ or less is at the end of the feeder. As the capacity of the PV system increases the total power loss of the feeder decreases. The optimal location is changing as the capacity of the PV system changes. As the installed capacity of 


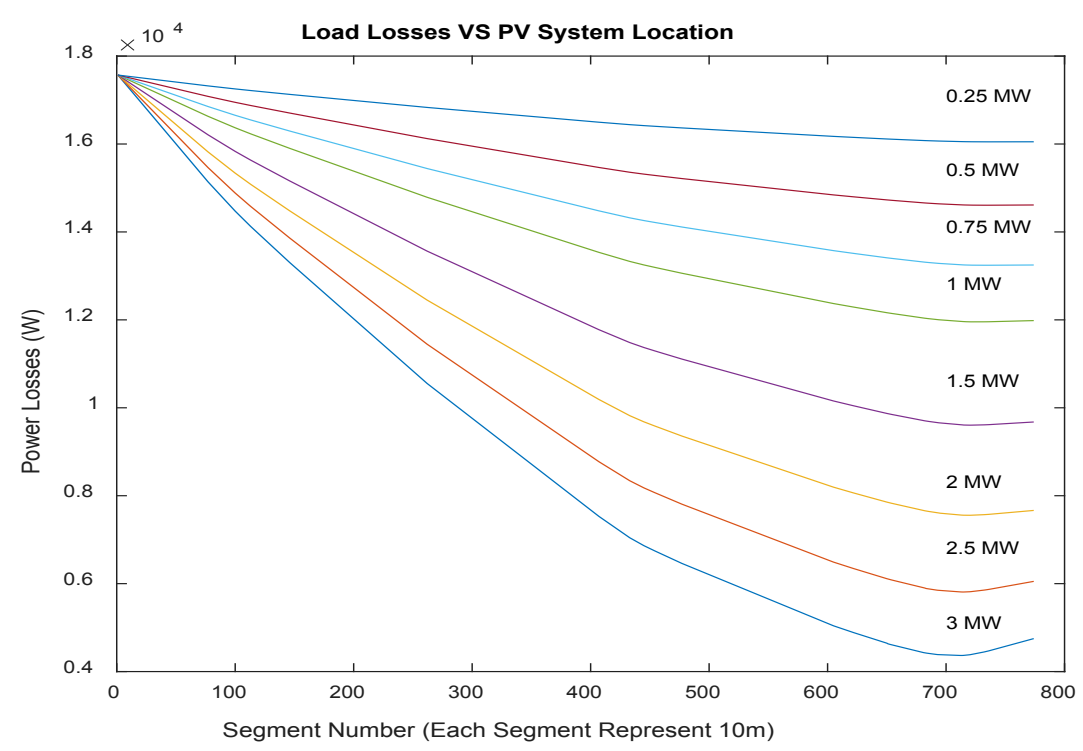

Figure 8. Optimal bus to connect the PV systems (Feeder 1).

PV system gets smaller, the optimal location gets further in the feeder. The slope of the line increased sharply at three locations. The first one is between segment 100 and 200, the second location is between segment 400 and 500, and the last one is at the end of the feeder. The reason is the concentration of load at these locations. As the curves reach the end of the feeder, the slope change its direction to rise up, means the power loss start to increase as the installed PV system location gets further after the optimal location. Table 2 summarizes the results.

Table 2 illustrates that as the total PV systems get smaller, the optimal place would be at the end of the feeder. The power loss is decreasing as the installed PV systems getting bigger. The differences between the optimal locations for each case related to the load distribution over the feeder. Similarly, the differences in power loss are related to the same reason. The result would be different based on the distribution of the load over the feeder and the length of the cable.

\subsubsection{Feeder 2 Result}

For Feeder 2 of the circuit, in all the cases, the optimal location to install a PV system of size $3 \mathrm{MW}$ or less is at the end of the feeder.

As the capacity of the PV system increase the power loss of the feeder decrease. The optimal location is changing as the capacity of the PV system changes, see Figure 9. As the installed capacity of PV system gets smaller, the optimal location gets further in the feeder. The slope of the line kept constant till it reaches segment 370 , where the part before is a load free. The slope increased at two locations, between segment 370 and 450 , the second location is from segment 570 to nearly 700 . The reason is because of the concentration of load at these locations. For the 2.5 and $3 \mathrm{MW}$ systems capacity, as the curves reach the end of the feeder, the slope changes its direction to rise up, means the power loss start to increase as the installed PV system location gets further after the optimal location, just like the situation in Feeder 1. Table 3 summarizes the result. 
Table 2. Feeder 1 results summary.

\begin{tabular}{cccc}
\hline Capacity of PV System (MW) & Optimal Location $(\mathrm{m})$ & Losses $(\mathrm{kW})$ & (Loss/Load) Percentage \\
\hline 0.25 & 7330 & 16.050 & $0.2559 \%$ \\
0.5 & 7210 & 14.610 & $0.2330 \%$ \\
0.75 & 7210 & 13.245 & $0.2113 \%$ \\
1 & 7150 & 11.961 & $0.1908 \%$ \\
1.5 & 7130 & 9.6131 & $0.1534 \%$ \\
2 & 6940 & 7.6090 & $0.1215 \%$ \\
2.5 & 6920 & 5.8802 & $0.0939 \%$ \\
3 & 6920 & 4.4462 & $0.0710 \%$ \\
\hline
\end{tabular}

Table 3. Feeder 2 results summary.

\begin{tabular}{cccc}
\hline Capacity of PV System (MW) & Optimal Location $(\mathrm{m})$ & Losses $(\mathrm{kW})$ & (Loss/Load) Percentage \\
\hline 0.25 & 7970 & 15.386 & $0.3134 \%$ \\
0.5 & 7950 & 13.911 & $0.2835 \%$ \\
0.75 & 7940 & 12.520 & $0.2552 \%$ \\
1 & 7740 & 11.296 & $0.2303 \%$ \\
1.5 & 7390 & 8.8651 & $0.1808 \%$ \\
2 & 7330 & 6.7916 & $0.1386 \%$ \\
2.5 & 7380 & 5.0375 & $0.1028 \%$ \\
3 & 7280 & 3.5961 & $0.0734 \%$ \\
\hline
\end{tabular}

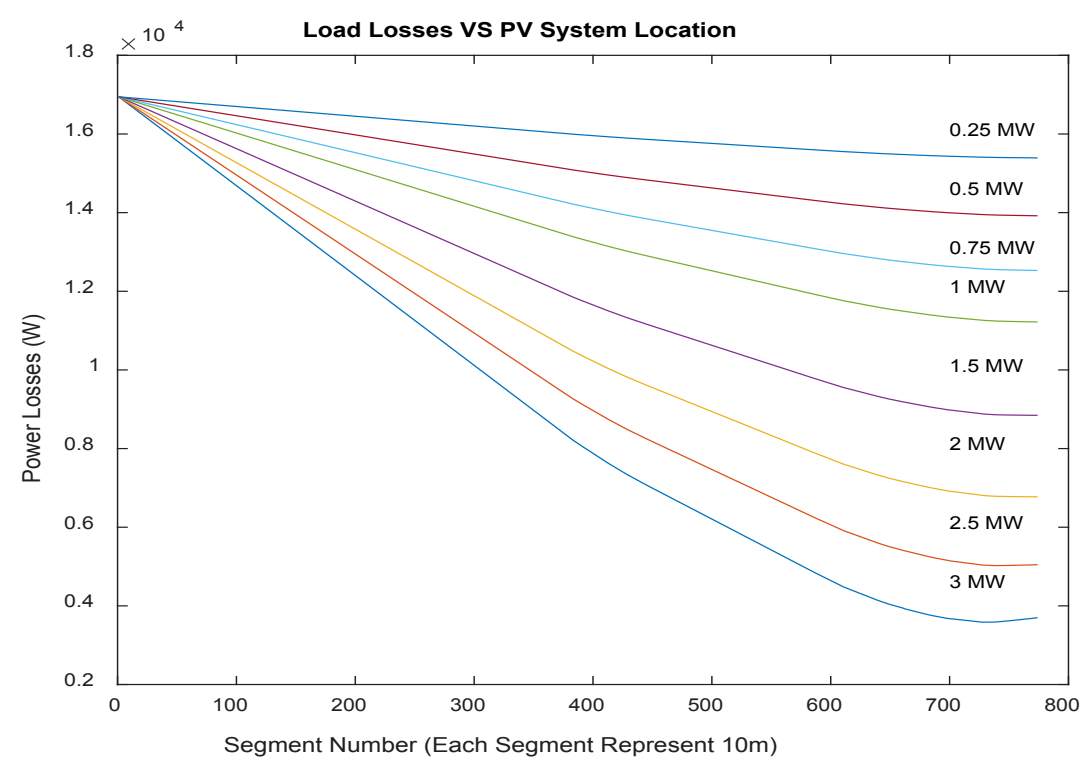

Figure 9. Optimal bus to connect the PV systems (Feeder 2).

Table 3 illustrates that as the total PV systems get smaller, the optimal place would be at the end of the feeder. The power loss is decreasing as the installed 
PV systems getting bigger. As shown in the table, all optimal locations are determined to be at the furthest segments, which are much predicted based on the load distribution over the feeder. The result would be different based on the distribution of the load over the feeder and the length of the cable.

\subsection{Harmony Search Algorithm}

The HS algorithm, which is based on random inputs, is used also to find the optimal allocation of PV system. A MATLAB code was developed to apply the harmony search algorithm. A system of $1 \mathrm{MW}$ is installed in both Feeder 1 and

2. Table 4, summarizes the results,

The HS algorithm results are comparable for the two feeders. For the first feeder of the circuit, the optimal location of installing a $1 \mathrm{MW}$ PV system is the same location resultant by two methods, whereas, for the second feeder, the optimal locations were different but they are close to each other. For the power loss percentage, the results were very close to the two methods.

\section{The Impact of the Connected PV Systems on Power System Stability}

The rapid expansion of electrical network requires improvement of the quality and reliability of power system. Voltage stability is a major issue which affects the end-users especially in the industrial sector. Connecting another source to the network would have its effect on stability of the power system [9]. The fault current values would also be affected by the penetration of DG [10].

After defining the optimal placement of PV systems in terms of circuit power loss, the impact of connecting the PV system is studied. This research is focusing on the impact on voltage instability, power factor and fault current calculation.

The used simulation program is MATLAB through Simulink tool. The case study circuit is modeled then tested.

\subsection{Impact on Voltage Instability}

A fundamental requirement in the operation of a power system is that power flow and bus voltages are maintained within acceptable limits throughout the network despite changes in load or available transmission and generation resources. Furthermore, the system needs to exhibit an ability to remain in a state of operating equilibrium under normal operating conditions and to regain an

Table 4. Compression between the two methods.

\begin{tabular}{ccccc}
\hline Method & Feeder & $\begin{array}{c}\text { Optimal } \\
\text { Location }(\mathrm{m})\end{array}$ & Losses $(\mathrm{kW})$ & $\begin{array}{c}\text { (Loss/Load) } \\
\text { Percentage }\end{array}$ \\
\hline Maximal Power Loss Reduction & Feeder 1 & 7200 & 11.956 & $0.1908 \%$ \\
Harmony Search Algorithm & & 7200 & 11.989 & $0.1911 \%$ \\
Maximal Power Loss Reduction & Feeder 2 & 7740 & 11.296 & $0.2303 \%$ \\
Harmony Search Algorithm & & 7530 & 11.256 & $0.2300 \%$ \\
\hline
\end{tabular}


acceptable state of equilibrium after being subjected to a disturbance. The disturbance may be associated with an outage of a generator, transformer, line or loads [11].

Several PV systems were connected to the feeders, ranging from $0.25 \mathrm{MW}$ up to $1 \mathrm{MW}$. Table 5 shows the percentage of improvement of voltage at the far end bus for each feeder.

The voltage measurements after connecting $0.25,0.5,0.75$ and 1 MW PV system increased by a small percentage which is reasonable based on the capacitance nature of the underground cables and the length of the cable. The effect would be different if a larger capacity PV system was connected to the feeder, or if the characteristic of the feeders is different.

\subsection{The Effect on Power Factor}

Power quality is one of the main concerns of both power plant owners and Network System Operators [12].

In reference [13], the researcher considered a 69-bus, 8-lateral distribution feeder. He considered four different PV penetrations: $190 \mathrm{~kW}, 380 \mathrm{~kW}, 570 \mathrm{~kW}$ and $760 \mathrm{~kW}$. Assuming that all PV systems are multiples of the standard PV "building block" of $2 \mathrm{~kW}$, i.e. for a $760 \mathrm{~kW}$ PV penetration, 380 "building blocks" are scattered across the feeder.

A significant improvement of nearly $3 \%$ increasing happened to the power factor over the substation level. The reasons are because of the characteristic of the feeder itself, length, load distribution, etc. The second reason is the optimal distribution of small sizes PV system across the feeder [13].

For the case study circuit of this research, the PV system is installed at one optimal location defined in the first part of the research. The exciting power factor measured at the load end, without connecting the PV system, it was ranging from 0.86 up to 0.93 . Table 6 shows the percentage of improvement of power factor value.

Although the improvement is a very slight and it will not reflect a huge improvement, but in the long period, it will help to reduce the losses. In Feeder 2 of the circuit, no bus had experienced an improvement of 0.0002 in p.f. reading, which is reasonable due to the concentration of load at the end of the feeder. Due to the installation PV system in one location of the circuit, the readings of power factor for both feeders did not improve significantly as in reference [13],

Table 5. Percentage of improvement after connecting the PV system.

\begin{tabular}{ccccc}
\hline \multirow{2}{*}{ Bus } & \multicolumn{4}{c}{ PV System Capacity } \\
\cline { 2 - 4 } & $250 \mathrm{~kW}$ & $500 \mathrm{~kW}$ & $750 \mathrm{~kW}$ & $1 \mathrm{MW}$ \\
\hline \multirow{2}{*}{22} & Feeder 1 & \\
& $0.66 \%$ & $0.66 \%$ & $0.73 \%$ & $0.81 \%$ \\
20 & $0.22 \%$ & Feeder 2 & $0.44 \%$ \\
\hline
\end{tabular}


Table 6. Power factor's percentage of improvement.

\begin{tabular}{cccccc}
\hline \multirow{2}{*}{ Feeder } & Bus & \multicolumn{4}{c}{ PV System Capacity } \\
\cline { 2 - 6 } & & $250 \mathrm{~kW}$ & $500 \mathrm{~kW}$ & $750 \mathrm{~kW}$ & $1 \mathrm{MW}$ \\
\hline 1 & 1 to 7 & 0 & 0 & 0 & 0 \\
& 8 to 11 & 0 & 0 & 0 & $0.11 \%$ \\
& 12 to 16 & 0 & 0 & $0.11 \%$ & $0.11 \%$ \\
& 17 to 22 & 0 & $0.11 \%$ & $0.11 \%$ & $0.23 \%$ \\
\hline & 1 to 14 & 0 & 0 & 0 & 0 \\
& 15 to 18 & 0 & 0 & 0 & $0.11 \%$ \\
& 19 to 20 & 0 & 0 & $0.11 \%$ & $0.11 \%$ \\
\hline
\end{tabular}

which had several small sizes of PV systems distributed over the case-study feeder.

The customers will also be benefits as they are paying only for the active power. This improvement will reduce the reactive power in the circuit. The low power factor causes the utility to have to increase its generation and transmission capacity in order to handle this extra demand. By raising the power factor, the consumption of reactive power will be less. This results in less active in KW, which equates to a money savings for both the utility company and the customers [14].

\subsection{The Impact on Protection}

Introduction of DG to the traditional power systems changes the radial passive distribution network into active network. Thus, it changes the value of fault current and duration, the current flow no longer unilaterally from the grid station bus flows into the load. The failure behavior of DG itself also will have an impact on system operation and protection [11]. In the case of a short circuit on the network, the short circuit current could theoretically be partly provided by the PV generator, which would disturb the detection of the fault by the protection devices provided on the network.

The PV system is installed at the optimal location defined by the maximum loss reduction. Since the occurrence of the three phase fault represented the highest impact on the short circuit level, it is considered in this research. Three cases were studied, $1 \mathrm{MW}, 2 \mathrm{MW}$ and $3 \mathrm{MW}$ systems were connected respectively.

1) Feeder 1

For the first feeder of the circuit, the optimal location of connecting the PV system is at bus 18 for a 1 MW system at bus 16 for both 2 MW and 3 MW systems. Figure 10 shows the percentage of short circuit current increasing.

As shown in Figure 10, the short circuit current increased when PV system is erected to the feeder. When connecting a $1 \mathrm{MW} \mathrm{PV}$ system, the value of short circuit current at the connection bus increased by $1 \%$. If the connected PV system is a $2 \mathrm{MW}$ system then, the short circuit current value will be increased by 
7\%. While a $3 \mathrm{MW}$ PV system would result in an increasing of short circuit current value by $7.5 \%$. These results will not affect the network design specification since such an increase in the fault current is already counted. The increasing in short circuit current value was affected by the location of PV system. If the capacity of the PV increases, the optimal location will be closer to the primary station; thus the short circuit current will be higher.

2) Feeder 2

For the second part of the circuit, the optimal location of connecting the PV system is at bus 19 for a $1 \mathrm{MW}$ system, at bus 17 for a $2 \mathrm{MW}$, while for a $3 \mathrm{MW}$ systems, the optimal location is at bus 16 .

As shown in Figure 11, the short circuit current increased when PV system is erected to the feeder. When connecting a $1 \mathrm{MW}$ PV system, the value of short circuit current at the connection bus increased by $1 \%$. If the connected PV system is a $2 \mathrm{MW}$ system then, the short circuit current value will be increased by $5 \%$. While a $3 \mathrm{MW}$ PV system would result in an increasing of short circuit current value by $9 \%$. These results will not affect the network design specification since such an increase in the fault current is already counted. The increasing in short circuit current value was affected by the location of PV system. If the capacity of the PV increases, the optimal location will be closer to the primary station; thus the short circuit current will be higher.

Generally, it is considered that PV generators connected to distribution networks do not contribute significantly to short circuit fault current, in case such events occur on the distribution system side. This is because the short-circuit

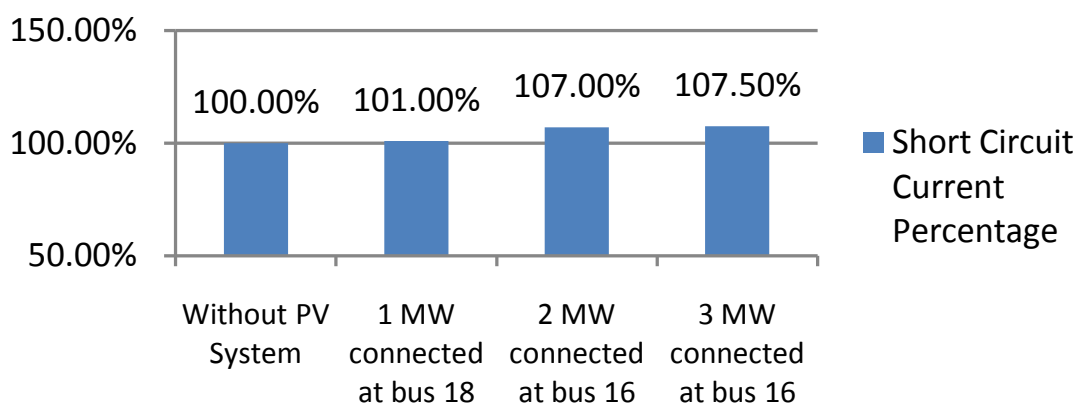

Figure 10. The percentage of short circuit current increasing due to PV system connecting for Feeder 1.

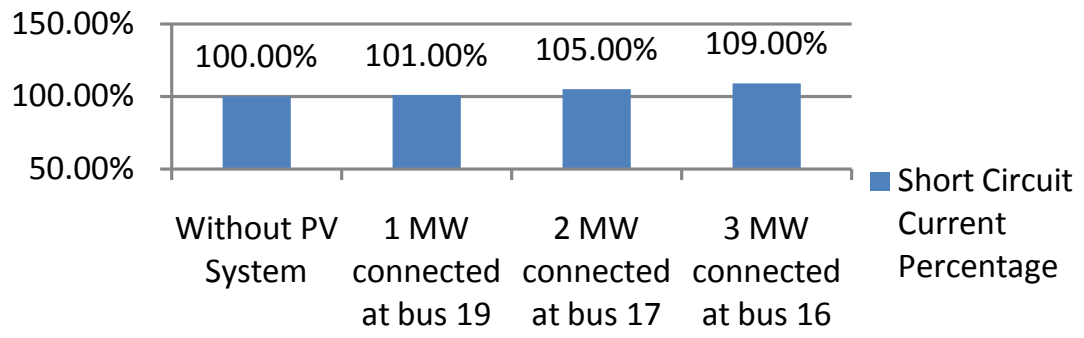

Figure 11. The percentage of short circuit current increasing due to PV system connecting for Feeder 2. 
current of a PV array is $10 \%-20 \%$ more than the rated maximum output current at most, inverters are normally equipped with under voltage relays and current controlled types mainly used in PVDG have over-current limiting in case of disturbances on the distribution system side.

From the results above of short circuit current values with and without the interconnection of PV systems, it is obvious that there is no significant impact would be introduce by interconnecting a PV systems of less than $3 \mathrm{MW}$ to such feeders.

\section{Conclusion}

The aim of this proposed work is to identify the optimal locations of PV systems ranging from $250 \mathrm{~kW}$ up to $3 \mathrm{MW}$ to be connected and integrated to the $\mathrm{MV}$ network. A typical underground $13.8 \mathrm{kV}$ circuit among Riyadh City network was selected to be the case study application. The circuit consists of three feeders, two of them are main source of power and the third is a spare one. The main two feeders were implemented in the research. The used method is a numerical one which tries all the possibilities and gives the optimal location based on maximal power loss reduction. The simulation was done using a unique MATLAB code. A heuristic method which is the Harmony Search Algorithm (HAS) was used to determine the optimal location and compare the two results. Some field experimental observations and calculations using the HAS were also performed and documented. In both feeders the result were comparable, the optimal locations for connecting the PV system were at the end of each feeder, or specifically, at load point side. The optimal location is getting as closer as possible to the power source as the system capacity becomes larger.

\section{Conflicts of Interest}

The authors declare no conflicts of interest regarding the publication of this paper.

\section{References}

[1] Nasir, M., Shahrin, N., Bohari, Z., Sulaima, M. and Hassan, M. (2014) A Distribution Network Reconfiguration Based on PSO: Considering DGs Sizing and Allocation Evaluation for Voltage Profile Improvement. IEEE Student Conference on Research and Development, Penang, 16-17 December 2014. https://doi.org/10.1109/SCORED.2014.7072981

[2] American Public Power Association (2013) Distributed Generation. Washington DC.

[3] Heydt, G.T. (2010) The Next Generation of Power Distribution Systems. IEEE Transactions on Smart Grid, 1, 225-235. https://doi.org/10.1109/TSG.2010.2080328

[4] Ezysolare.com (2016) Trend Analysis on Solar PV Module Prices. http://www.ezysolare.com/blog/knowledge-center/trend-analysis-on-solar-pv-mod ule-prices

[5] Ackermann, T., Andersson, G. and Soder, L. (2001) Distributed Generation: A De- 
finition. Electric Power Systems Research, 57, 195-204.

https://doi.org/10.1016/S0378-7796(01)00101-8

[6] Saudi Electricity Company (2015) Transmission Materials Standard Specifications No. 01-TMSS-01 REV.02. Riyadh.

[7] Saudi Electricity Company (2013) SEC Distribution Materials Specifications No. 11-SDMS-03 REV.02. Riyadh.

[8] Labrini, H., Gad, A., ElShatshat, R.A. and Salama, M.M.A. (2015) Dynamic Graph Based DG allocation for Congestion Mitigation in Radial Distribution Networks. IEEE Power \& Energy Society General Meeting, Denver, 26-30 July 2015. https://doi.org/10.1109/PESGM.2015.7286611

[9] Kuang, H., Li, S. and Wu, Z. (2011) Discussion on Advantages and Disadvantages of Distributed Generation Connected to the Grid. International Conference on Electrical and Control Engineering, Yichang, 16-18 September 2011.

[10] Gurkiran, K. and Mohammad, V. (2006) Effects of Distributed Generation (DG) Interconnections on Protection of Distribution Feeders. Power Engineering Society General Meeting, Montreal.

[11] Chiradeja, R. and Ramakumar, R. (2004) An Approach to Quantify the Technical Benefits of Distributed Generation. IEEE Transactions on Energy Conversion, 19, 764-773. https://doi.org/10.1109/TEC.2004.827704

[12] Camacho, A., Castilla, M., Miret, J., Matas, J., Guzman, R., Sousa-Pérez, O., Martí, P. and García de Vicuña, L. (2013) Control Strategies Based on Effective Power Factor for Distributed Generation Power Plants during Unbalanced Grid Voltage. 39th Annual Conference of the IEEE, Vienna, 10-13 November 2013. https://doi.org/10.1109/IECON.2013.6700318

[13] Begovic, M., Pregelj, A., Rohatgi, A. and Novosel, D. (2001) Impact of Renewable Distributed Generation on Power Systems. Proceedings of the Hawaii International Conference on System Sciences, Maui, 6 January 2001.

[14] Lucian, L., Dulăua, M. and Abrudean, D. (2013) Effects of Distributed Generation on Electric Power Systems. The 7th International Conference Interdisciplinarity in Engineering, Târgu Mureș, 10-11 October 2013.

\section{Nomenclature}

Loop Distribution Network can be seen as a medium voltage network topology where the circuit is connected in loop with the existing of Normal Open Point (NOP) for each circuit to avoid the load flow and keep only one source of current which can be changed operationally by switching ON and OFF the RMU switches either manually or automatically.

Feeder: Can be defined as the part of the circuit where all parts in the feeder are fed by a single source. Also, feeder can be considered to be the part from the source point (Primary Station) up to the NOP. 